\title{
KEANEKARAGAMAN JENIS BURUNG DIURNAL DI DESA BUKIT BATU KECAMATAN SUNGAI KUNYIT KABUPATEN MEMPAWAH
}

\author{
The Diversity of Diurnal Bird Species in Bukit Batu Village Sungai Kunyit Sub-District \\ Mempawah Regency
}

\author{
Jimmi Kurniawan, Hari Prayogo, Ratna Herawatiningsih \\ Fakultas Kehutanan Universitas Tanjung Pura Jl. Daya Nasional, Pontianak 78124 \\ E-mail: jimmykurniawan20@ gmail.com
}

\begin{abstract}
The bird is an indicator for the quality of the environment and has a role in ensuring the passage of tropical forest regeneration process naturally in Indonesia. The bird is one of the animals with the highest diversity in Indonesia. The purpose of this research is to examine the diversity of diurnal birds and can be relied upon the efforts of wildife preservation process. This research method using a combination of methods to calculate point (Point Count) or IPA (Ponctuele d'Abundance Index - Index of abundance at that point) and the method of lines (Transect), observations conducted quietly at some point later noted the encounter against birds, observations using the six-point count/observation station. The whole of the observations was on track (Transect) the length of 1,800 meters. The results of this study that the diurnal bird species diversity in Bukit Batu village Sungai Kunyit Subdistrict Mempawah Regency. Course found 26 species of birds in three diurnal habitat types with a total of 420 individuals. The value of the index of diversity $\left(H^{\prime}\right)$ type on every type of ecosystem is on the secondary, 2.19 swamp forest, shrub swamps 2.32, and dry land farming 2.18. This indicates that each type has the different diversity of habitat.
\end{abstract}

Keyword: Birds, Diurnal, Ecosystems, Indicators and Species diversity

\section{PENDAHULUAN}

Burung merupakan salah satu hewan dengan keanekaragaman tertinggi di Indonesia. Lembaga pelestarian burung yaitu Burung Indonesia, mencatat keragaman jenis burung di Indonesia pada 2014 meningkat menjadi 1.666 jenis. Tahun 2013, Indonesia tercatat memiliki 1.605 jenis burung. Penambahan tersebut sebagian besar merupakan hasil pemisahan jenis yang sudah ada, karena perbedaan morfologi maupun suara berdasarkan hasil penelitian terbaru. Kekayaan tidak terhingga ini menempatkan Indonesia sebagai negara dengan keragaman burung terbesar nomor empat di dunia (Susanti, 2014).
Burung merupakan indikator bagi kualitas lingkungan dan berperan dalam menjamin berjalannya proses regenerasi hutan tropis secara alami di Indonesia (Utomo, 2010). Burung juga memiliki peran penting dalam penyerbukan berbagai bunga di hutan, sehingga keberadaannya di ekosistem dibutuhkan (Hernowo, 1989). Burung merupakan salah satu komponen ekosistem yang memiliki peran penting dalam mendukung keberlangsungan siklus organisme. Keadaan ini dapat dilihat dari rantai makanan yang membentuk sistem kehidupan dengan komponen ekosistem lainnya seperti tumbuhan dan serangga. Alih fungsi ekosistem yang terjadi saat ini menyebabkan sumber daya alam berada 
dalam status kemunduran (MacKinnon et al., 2010).

Satwa liar Burung (Avifauna) merupakan salah satu sumber daya alam yang memiliki peranan penting bagi kehidupan manusia, baik ditinjau dari segi ekonomi, rekreasi dan ilmu pengetahuan (Hernowo dan Prasetyo, 1989). Keterbatasan jumlah burung di hutan tropika disebabkan oleh kompleksnya interaksi ekologi yang erat kaitannya dengan komunitas burung. Hal itu juga dipengaruhi oleh faktor tingkat suksesi yang telah dicapai oleh suatu hutan, keadaan curah hujan yang berhubungan dengan populasi serangga dan musim buah, keanekaragaman habitat serta hubungan antara satu habitat dengan habitat lainnya sebagian besar dipengaruhi oleh faktor fisik berupa keadaan iklim serta struktur maupun komposisi vertikal dari tajuk pada masing-masing habitat (Mackinnon, 1990).

Kawasan hutan di Desa Bukit Batu Kecamatan Sungai Kunyit Kabupaten Mempawah merupakan habitat alami berbagai jenis tumbuhan dan burung. Kawasan ini dimanfaatkan oleh beragam jenis burung baik sebagai tempat untuk mencari makan, minum, berlindung, beristirahat maupun tempat bersarang serta berkembang biak. Kekayaan sumberdaya alam hayati dan ekosistem yang berada di kawasan hutan saat ini telah dirasakan oleh masyarakat dalam keadaan cenderung menurun akibat dari pemanfaatan sumber daya alam yang berlebihan dan kurang bijaksana. Dampak buruk dari hal tersebut tentunya dapat mengakibatkan musnahnya berbagai jenis tumbuhan dan burung. Sampai saat ini belum ada penelitian tentang keanekaragaman jenis burung di lokasi tersebut. Untuk itu pada kawasan itu perlu dilakukan peneltian, sehingga dapat memperoleh informasi yang lengkap mengenai keanekaragaman jenis satwa burung diurnal. Tujuan penelitian ini adalah untuk mengkaji keanekaragaman jenis burung diurnal di Desa Bukit Batu Kecamatan Sungai Kunyit Kabupaten Mempawah. Penelitian ini diharapkan dapat memberikan manfaat berupa informasi tentang keanekaragaman jenis burung diurnal berdasarkan tipe ekosistem dan dapat dijadikan dasar upaya dalam pelestarian satwa burung.

\section{METODE PENELITIAN}

Penelitian ini dilaksanakan pada tanggal 16 Februari - 2 Maret 2018 di Desa Bukit Batu Kecamatan Sungai Kunyit Kabupaten Mempawah, sebagai objek dalam penelitian ini adalah jenis burung diurnal pada beberapa tipe habitat di kawasan hutan Desa Bukit Batu. Adapun alat dan bahan yang digunakan dalam penelitian ini peta lokasi penelitian, buku panduan, binokuler, kompas, kamera, GPS, jam, parang, alat tulis dan tally sheet. Metode yang digunakan dalam penelitian ini adalah metode kombinasi antara metode titik hitung (Point Count) atau IPA (Indices Ponctuele d'Abundance - Indeks Kelimpahan pada Titik) dan metode (Transect) jalur, pengamatan dilakukan dengan diam pada titik tertentu kemudian mencatat perjumpaan terhadap burung. Parameter yang diukur yaitu jenis, jumlah, dan waktu. Dalam pengamatan menggunakan enam titik hitung (Point Count)/Stasiun pengamatan. Seluruh stasiun pengamatan tersebut berada dalam 
jalur (transect) yang panjangnya 1.800 meter dengan radius pengamatan 30 meter, serta jarak antar titik hitung (Point Count) menggunakan waktu 30 menit / Point Count. Rentang waktu pengamatan dilakukan selama 30 menit, 15 menit untuk pengamatan disetiap titik dan 15 menit adalah waktu untuk berjalan ke titik pengamatan selanjutnya. Setiap jenis burung yang dijumpai pada setiap titik dalam jalur pengamatan dicatat dengan sesuai jenisnya.

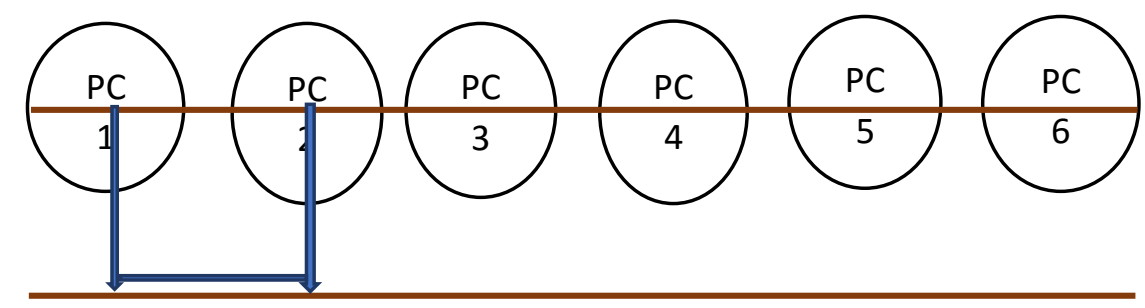

Gambar 1. Penempatan titik pengamatan menggunakan metode kombinasi antara metode titik hitung dan metode jalur. (Observation point placement method using a combination of point count method and transect method).

Pengamatan dilakukan pada pagi hari pukul 06.00 - 09.00 WIB dan pada sore hari pukul $15.00-18.00$ WIB. Pengamatan dilakukan secara berulang sebanyak 3 kali pengulangan untuk setiap lokasi pengamatan. Perhitungan populasi dengan menghitung langsung jumlah burung yang diamati dengan data populasi tertinggi yang digunakan untuk perhitungan indeks keanekaragaman.

\section{Analisis data}

1. Indeks keanekaragaman jenis

Keanekaragaman jenis dapat diketahui dengan Indeks Keanekaragaman ShannonWienner yaitu dengan rumus (Krebs, 1978; Syafrudin, 2011).

$$
\mathbf{H}^{\prime}=-\sum \text { pi ln pi }
$$

Keterangan :

$\mathrm{H}^{\prime} \quad=$ Indeks Keanekaragaman Jenis

Burung

$\mathrm{Pi}=$ Jumlah proporsi kelimpahan spesies burung

Ln = Logaritma natural
Kreteria nilai indeks keanekaragaman Shannon - Wienner, apabila:

$\mathrm{H}^{\prime} \leq 1=$ keanekaragaman rendah

$1<\mathrm{H}^{\prime}<3=$ keanekaragaman sedang

$\mathrm{H}^{\prime} \geq 3$ = keanekaragaman tinggi (Odum, 1994; Handari, 2012)

2. Indeks kemerataan

Indeks kemerataan digunakan untuk mengetahui kemerataan setiap spesies dalam setiap komunitas yang dijumpai.

$\mathrm{E}=\frac{\mathrm{H}^{\prime}}{\operatorname{Ln}(\mathrm{S})}$

Keterangan :

$\mathrm{H}^{\prime}$ = Keanekaragaman

$\mathrm{E}=$ Indeks kemerataan

$\mathrm{S}=$ Jumlah spesies

Rumus ini digunakan karena nilai H' sudah diperoleh sebelumnya sehingga lebih mudah dalam perhitungannya. Kriteria indeks kemerataan (Daget, 1976;

Solahudin, 2003) adalah sebagai berikut :

$0<\mathrm{J} \leq 0,5 \quad$ : Komunitas tertekan

$0,5<\mathrm{J} \leq 0,75:$ Komunitas labil 
$0,75<\mathrm{J} \leq 1 \quad$ : Komunitas stabil.

3. Indeks kesamaan jenis

Dihitung dengan menggunakan rumus (Soerianegara dan indrawan, 1982; Odum, 1993; Indriyanto, 2006). Hal ini untuk mengetahui ada tidaknya perbedaan komposisi spesies burung berdasarkan tipe hutan produksi yang diteliti.

$\mathrm{IS}=2 \mathrm{C} /(\mathrm{A}+\mathrm{B})$

Keterangan :

$\mathrm{C}=$ jumlah spesies yang sama dan terdapat pada kedua komunitas

$\mathrm{A}=$ jumlah spesies yang dijumpai pada lokasi 1

$\mathrm{B}=$ jumlah spesies yang dijumpai pada lokasi 2.

IS $0 \%=$ komposisi jenis berbeda

IS $>50 \%=$ komposisi relatif sama

\section{Indeks kepadatan jenis burung}

Analisis kepadatan burung menggunakan persamaan dalam Reynold et al. (1980) dan Santosa (1993).

Dugaan kepadatan jenis burung ke-i pada tipe hutan (Di)

$$
\left(D_{i}\right)=\frac{\begin{array}{c}
\text { jumlah individu } \\
\text { jenis ke-i (individu) }
\end{array}}{\begin{array}{c}
\text { luas total transek } \\
\text { penelitian pada tipe } \\
\text { hutan ke-j }
\end{array}}
$$

Nilai dugaan rata-rata kepadatan burung pada tipe hutan $(\mathrm{Dj})$

$$
D j=\sum_{\frac{i}{n}}^{n} D i \ldots \ldots \ldots
$$

$\mathrm{n}=$ jumlah jenis burung

i $=$ jumlah individu

$\mathrm{Dj}=$ kepadatan jenis burung

$\mathrm{Di}=$ nilai dugaan rata-rata

\section{HASIL DAN PEMBAHASAN}

Hasil penelitian ini ditemukan 26 jenis burung diurnal dengan jumlah keseluruhan 420 individu, terdiri dari 15 famili. Setiap jalur dilakukan pengulangan sebanyak 3 kali ulangan yaitu 1 jalur pada tipe ekosistem hutan rawa sekunder dengan vegetasi yang masih rapat, jalur 2 pada ekosistem semak belukar rawa, dan jalur 3 pada pertanian lahan kering.

\begin{tabular}{|c|c|c|c|c|c|c|c|c|c|c|c|}
\hline \multirow{2}{*}{ No } & \multirow{2}{*}{ Famili } & \multirow{2}{*}{$\begin{array}{l}\text { Indonesia } \\
\text { name }\end{array}$} & \multirow{2}{*}{$\begin{array}{l}\text { English } \\
\text { name }\end{array}$} & \multirow{2}{*}{$\begin{array}{l}\text { Scientifiec } \\
\text { name }\end{array}$} & \multicolumn{3}{|c|}{ Line transect } & \multicolumn{4}{|c|}{ Status perlindungan } \\
\hline & & & & & 1 & 2 & 3 & CITES & IUCN & RI & MIG/and \\
\hline 1 & Columbidae & Merpati hias & $\begin{array}{l}\text { Cinnamon } \\
\text { headed } \\
\text { green } \\
\text { pigeon }\end{array}$ & $\begin{array}{l}\text { Treron } \\
\text { fulvicollis }\end{array}$ & 15 & 15 & 2 & II & NT & & $\mathrm{BR}$ \\
\hline 2 & Cuculidae & Butbut besar & $\begin{array}{l}\text { Lesser } \\
\text { coucal }\end{array}$ & $\begin{array}{l}\text { Centropus } \\
\text { bengalensis }\end{array}$ & 6 & 0 & 2 & & $\mathrm{LC}$ & & $\mathrm{BR}$ \\
\hline 3 & Pycnonotidae & $\begin{array}{l}\text { Merbah } \\
\text { cerucuk }\end{array}$ & $\begin{array}{l}\text { Yellow } \\
\text { vented } \\
\text { bulbul }\end{array}$ & $\begin{array}{l}\text { Pycnonotus } \\
\text { goiavier }\end{array}$ & 14 & 11 & 20 & & $\mathrm{LC}$ & & $\mathrm{BR}$ \\
\hline 4 & Rallidae & keruak putih & $\begin{array}{l}\text { White } \\
\text { breasted } \\
\text { waterhen }\end{array}$ & $\begin{array}{l}\text { Amaurornis } \\
\text { phoenicurus }\end{array}$ & 5 & 0 & 0 & & $\mathrm{LC}$ & & $\mathrm{BR}+\mathrm{M}$ \\
\hline
\end{tabular}

Tabel 1. Daftar Jenis Burung yang Ditemukan di lokasi Penelitian dan Status Perlindungannya. (List of bird species found at the study site and protection status). 


\begin{tabular}{|c|c|c|c|c|c|c|c|c|c|c|c|}
\hline \multirow{2}{*}{ No } & \multirow{2}{*}{ Famili } & \multirow{2}{*}{$\begin{array}{l}\text { Indonesia } \\
\text { name }\end{array}$} & \multirow{2}{*}{$\begin{array}{l}\text { English } \\
\text { name }\end{array}$} & \multirow{2}{*}{$\begin{array}{l}\text { Scientifiec } \\
\text { name }\end{array}$} & \multicolumn{3}{|c|}{ Line transect } & \multicolumn{4}{|c|}{ Status perlindungan } \\
\hline & & & & & 1 & 2 & 3 & CITES & IUCN & RI & MIG/and \\
\hline 5 & Pycnonotidae & $\begin{array}{l}\text { Merbah } \\
\text { hitam }\end{array}$ & $\begin{array}{l}\text { Black and } \\
\text { white } \\
\text { bulbul }\end{array}$ & $\begin{array}{l}\text { pycnonotus } \\
\text { melanoleucos }\end{array}$ & 6 & 4 & 0 & & NT & & $\mathrm{BR}$ \\
\hline 6 & Cisticolidae & Prenjak jawa & $\begin{array}{l}\text { Yellow } \\
\text { bellied } \\
\text { prinia }\end{array}$ & $\begin{array}{l}\text { Prinia } \\
\text { flaviventris }\end{array}$ & 16 & 4 & 5 & & $\mathrm{LC}$ & & $\mathrm{BR}$ \\
\hline 7 & Columbidae & Tekukur & $\begin{array}{l}\text { Spotted } \\
\text { dove }\end{array}$ & $\begin{array}{l}\text { Sreptopelia } \\
\text { chinensis }\end{array}$ & 6 & 7 & 5 & & $\mathrm{LC}$ & & $\mathrm{BR}$ \\
\hline 8 & Sturnidae & Tiong mas & $\begin{array}{l}\text { Common } \\
\text { hill myna }\end{array}$ & $\begin{array}{l}\text { Gracula } \\
\text { religiosa }\end{array}$ & 4 & 0 & 0 & II & $\mathrm{LC}$ & $\mathrm{AB}$ & $\mathrm{BR}$ \\
\hline 9 & Picidae & Pelatuk & $\begin{array}{l}\text { White } \\
\text { bellied } \\
\text { wood } \\
\text { pecker }\end{array}$ & $\begin{array}{l}\text { Dryocopus } \\
\text { javensis }\end{array}$ & 6 & 6 & 0 & I & $\mathrm{LC}$ & & $\mathrm{BR}$ \\
\hline 10 & Hirundinidae & Layang batu & $\begin{array}{l}\text { Pacitific } \\
\text { swallow }\end{array}$ & $\begin{array}{l}\text { Hirundo } \\
\text { tahitica }\end{array}$ & 39 & 31 & 20 & & $\mathrm{LC}$ & & $\mathrm{BR}$ \\
\hline 11 & Meropidae & Kirik-kirik & $\begin{array}{l}\text { Blue } \\
\text { throated } \\
\text { bee eater }\end{array}$ & $\begin{array}{l}\text { Merops } \\
\text { viridis }\end{array}$ & 4 & 5 & 0 & & $\mathrm{LC}$ & & $\mathrm{BR}$ \\
\hline 12 & Rhipiduridae & Kipas belang & Pied fentail & $\begin{array}{l}\text { Rhipidura } \\
\text { javanica }\end{array}$ & 2 & 0 & 3 & & $\mathrm{LC}$ & $\mathrm{AB}$ & $\mathrm{BR}$ \\
\hline 13 & Pycnonotidae & $\begin{array}{l}\text { Merbah } \\
\text { belukar }\end{array}$ & $\begin{array}{l}\text { Olive- } \\
\text { Winged } \\
\text { bulbul }\end{array}$ & $\begin{array}{l}\text { Pycnonotus } \\
\text { plumosus }\end{array}$ & 2 & 6 & 0 & & $\mathrm{LC}$ & & $\mathrm{BR}$ \\
\hline 14 & Cisticolidae & $\begin{array}{l}\text { Cinenen } \\
\text { kelabu }\end{array}$ & $\begin{array}{l}\text { Ashy } \\
\text { throated } \\
\text { tailorbird }\end{array}$ & $\begin{array}{l}\text { Orthotomus } \\
\text { ruficeps }\end{array}$ & 0 & 2 & 0 & & $\mathrm{LC}$ & & $\mathrm{BR}$ \\
\hline 15 & Nectariniidae & $\begin{array}{l}\text { Burung } \\
\text { madu bakau }\end{array}$ & $\begin{array}{l}\text { Purple } \\
\text { throated } \\
\text { sunbird }\end{array}$ & $\begin{array}{l}\text { Leptocoma } \\
\text { sperata }\end{array}$ & 0 & 1 & 0 & & $\mathrm{LC}$ & $\mathrm{AB}$ & $\mathrm{BR}$ \\
\hline 16 & Pycnonotidae & $\begin{array}{l}\text { Merbah mata } \\
\text { merah }\end{array}$ & $\begin{array}{l}\text { Red eyed } \\
\text { bulbul }\end{array}$ & $\begin{array}{l}\text { Pycnonotus } \\
\text { brunneus }\end{array}$ & 0 & 26 & 0 & & $\mathrm{LC}$ & & $\mathrm{BR}$ \\
\hline 17 & Corvidae & Gagak hitam & $\begin{array}{l}\text { Slender } \\
\text { bellied } \\
\text { crow }\end{array}$ & Corvus enca & 0 & 3 & 0 & & $\mathrm{LC}$ & & $\mathrm{BR}$ \\
\hline 18 & Columbidae & Punai & $\begin{array}{l}\text { Pink } \\
\text { necked } \\
\text { green } \\
\text { pigeon }\end{array}$ & $\begin{array}{l}\text { Treron } \\
\text { vernans }\end{array}$ & 0 & 2 & 0 & & $\mathrm{LC}$ & & $\mathrm{BR}$ \\
\hline 19 & Estrildidae & Burung pipit & $\begin{array}{l}\text { Scaly } \\
\text { breasted } \\
\text { munia }\end{array}$ & $\begin{array}{l}\text { Lonchura } \\
\text { punctulata }\end{array}$ & 0 & 0 & 48 & & $\mathrm{LC}$ & & $\mathrm{BR}$ \\
\hline 20 & Pycnonotidae & $\begin{array}{l}\text { Merbah } \\
\text { berjambul }\end{array}$ & $\begin{array}{l}\text { Scooty } \\
\text { headed } \\
\text { bulbul }\end{array}$ & $\begin{array}{l}\text { Pycnonotus } \\
\text { aurigaster }\end{array}$ & 0 & 0 & 21 & & $\mathrm{LC}$ & & $\mathrm{BR}$ \\
\hline 21 & Dicaeidae & Cabai jawa & $\begin{array}{l}\text { Scarlet } \\
\text { throated } \\
\text { flower } \\
\text { pecker }\end{array}$ & $\begin{array}{l}\text { Dicaeum } \\
\text { cruentatum }\end{array}$ & 0 & 4 & 8 & & $\mathrm{LC}$ & & $\mathrm{BR}$ \\
\hline 22 & Accipitridae & $\begin{array}{l}\text { Elang laut } \\
\text { paruh putih }\end{array}$ & $\begin{array}{l}\text { White } \\
\text { bellied sea } \\
\text { eagle }\end{array}$ & $\begin{array}{l}\text { Haliaeetus } \\
\text { leucogaster }\end{array}$ & 0 & 0 & 1 & II & $\mathrm{LC}$ & & $\mathrm{BR}$ \\
\hline 23 & Nectariniidae & $\begin{array}{l}\text { Burung } \\
\text { madu kelapa }\end{array}$ & $\begin{array}{l}\text { Brown } \\
\text { throated } \\
\text { sunbird }\end{array}$ & $\begin{array}{l}\text { Anthreptes } \\
\text { malacensis }\end{array}$ & 0 & 0 & 1 & & $\mathrm{LC}$ & & $\mathrm{BR}$ \\
\hline 24 & Cisticolidae & $\begin{array}{l}\text { Cinenen } \\
\text { merah }\end{array}$ & $\begin{array}{l}\text { Rufous } \\
\text { tailed } \\
\text { tailorbird }\end{array}$ & $\begin{array}{l}\text { Orthotomus } \\
\text { sericeus }\end{array}$ & 0 & 0 & 12 & & $\mathrm{LC}$ & & $\mathrm{BR}$ \\
\hline
\end{tabular}




\begin{tabular}{|c|c|c|c|c|c|c|c|c|c|c|c|}
\hline \multirow{2}{*}{ No } & \multirow{2}{*}{ Famili } & \multirow{2}{*}{$\begin{array}{l}\text { Indonesia } \\
\text { name }\end{array}$} & \multirow{2}{*}{$\begin{array}{l}\text { English } \\
\text { name }\end{array}$} & \multirow{2}{*}{$\begin{array}{l}\text { Scientifiec } \\
\text { name }\end{array}$} & \multicolumn{3}{|c|}{ Line transect } & \multicolumn{4}{|c|}{ Status perlindungan } \\
\hline & & & & & 1 & 2 & 3 & CITES & IUCN & RI & MIG/and \\
\hline 25 & Passeridae & $\begin{array}{l}\text { Burung } \\
\text { gereja }\end{array}$ & $\begin{array}{l}\text { Eurasian } \\
\text { tree } \\
\text { sparrow }\end{array}$ & $\begin{array}{l}\text { Passer } \\
\text { montanus }\end{array}$ & 0 & 0 & 18 & & $\mathrm{LC}$ & & $\mathrm{BR}$ \\
\hline \multirow[t]{3}{*}{26} & Muscicapidae & $\begin{array}{l}\text { Kucicang } \\
\text { kampung }\end{array}$ & $\begin{array}{l}\text { Magpie } \\
\text { Robin }\end{array}$ & $\begin{array}{l}\text { Copsychus } \\
\text { saularis }\end{array}$ & 0 & 1 & 1 & & $\mathrm{LC}$ & & BR \\
\hline & & & $\begin{array}{l}\text { Jumlah } \\
\text { Individu }\end{array}$ & & 125 & 128 & 167 & & & & \\
\hline & & & mlah jenis & & 16 & 15 & & & & & \\
\hline
\end{tabular}

\section{Struktur Jenis Burung Pada} Masing-masing tipe ekosistem

Struktur jenis burung diurnal yang terdapat dalam areal pengamatan diketahui dari hasil perhitungan Indeks

Tabel 2. Indeks Keanekaragaman Jenis, Indeks Kemerataa Jenis, dan Indeks Kepadatan jenis. (Species Diversity Index, Equity Index, and Species Density Index).

\begin{tabular}{lccc}
\hline \multicolumn{1}{c}{ Indeks } & $\begin{array}{c}\text { Hutan Rawa } \\
\text { Sekunder }\end{array}$ & $\begin{array}{c}\text { Semak } \\
\text { Belukar Rawa }\end{array}$ & $\begin{array}{c}\text { Pertanian Lahan } \\
\text { Kering }\end{array}$ \\
\hline Indeks keanekaragaman & 2,19 & 2,32 & 2,18 \\
Indeks kemerataan & 0.85 & 0.83 & 0.80 \\
Nilai rata-rata kepadatan & 0,07 & 0,06 & 0,30 \\
\hline
\end{tabular}

Hasil analisa indeks keanekaragaman jenis, indeks kemerataan jenis, indeks kepadatan jenis, dan nilai dugaan rata-rata kepadatan jenis burung diurnal pada masing-masing ekosistem memberikan nilai yang sangat beragam. Keanekaragaman jenis burung diurnal yang tertinggi terdapat pada ekosistem semak belukar rawa dengan nilai $\bar{H}=$ 2,32. Kemerataan jenis burung diurnal yang terbesar terdapat pada ekosistem hutan rawa sekunder dengan nilai e = 0,85 , dan dugaan nilai rata-rata kepadatan jenis burung diurnal terbesar terdapat pada ekosistem pertanian lahan kering dengan nilai $\mathrm{Dj}=0,30$.

Dari hasil perhitungan indeks keanekaragaman jenis burung pada tipe ekosistem semak belukar rawa
Keanekaragaman Jenis, Indeks kemerataan, Indeks Kesamaan jenis, dan Indeks Kepadatan dapat dilihat pada Tabel 2 berikut : 
makan dan menjadikan tempat singgah di lokasi tersebut. burung tidak dapat beradaptasi dengan ekosistem buatan, ini sesuai dengan pendapat bahwa keanekaragaman jenis burung cenderung rendah dalam ekosistem yang terkendali secara fisik atau buatan dan cenderung tinggi dalam ekosistem yang diatur secara biologi (Ferianita, 2008).

\section{Indeks Kesamaan Jenis}

Dari hasil pengamatan yang dilakukan pada masing-masing tipe ekosistem dan dengan waktu pengamatan yang berbeda, terdapat kesamaan jenis burung yang ditemukan pada setiap jalur penelitian. Indeks kesamaan jenis dapat digunakan untuk melihat kesamaan antara jenis burung di setiap tipe vegetasi. Indeks kesamaan jenis burung paling tinggi ditemukan pada tipe ekosistem hutan rawa sekunder. Sedangkan indeks kesamaan jenis yang rendah adalah pada tipe ekosistem semak belukar rawa dan tipe ekosistem pertanian lahan kering.

Tabel 3. Indeks Kesamaan Jenis Pada Seluruh Tipe Ekosistem. (Similarity index on all ecosystem types).

\begin{tabular}{clccc}
\hline No & \multicolumn{1}{c}{ Habitat } & $\begin{array}{c}\text { Jenis Yang } \\
\text { Sama }\end{array}$ & $\begin{array}{c}\text { Jumlah } \\
\text { Jenis (A+B) }\end{array}$ & $\begin{array}{c}\text { Indeks } \\
\text { Kesamaan }\end{array}$ \\
\hline 1 & $\begin{array}{l}\text { Hutan rawa Sekunder - semak } \\
\text { belukar rawa }\end{array}$ & 9 & 28 & $64.29 \%$ \\
2 & $\begin{array}{l}\text { Hutan rawa Sekunder - Pertanian } \\
\text { lahan kering }\end{array}$ & 7 & 29 & $48.28 \%$ \\
3 & $\begin{array}{l}\text { Semak belukar rawa - Pertanian } \\
\text { lahan kering }\end{array}$ & 7 & 31 & $45.16 \%$ \\
\hline
\end{tabular}

Tinggi atau rendahnya kesamaan jenis pada masing-masing areal pengamatan disebabkan jenis makanan dan kondisi dari vegetasi yang berbeda, selera makan tiap jenis burung berbeda-beda, sebagian spesies burung memakan bagian dari tumbuh-tumbuhan, seperti : biji-bijian, nectar dan buah-buahan, ada beberapa spesies burung memakan hewan lain, seperti serangga dan ikan, setiap spesies hanya memakan jenis makanan tertentu saja, maka ia akan hidup dengan nyaman pada daerah yang sesuai dengan dirinya tersebut (Ardley, 1984).

Nilai indeks kesamaan jenis (IS) berkisar antara $0-100 \%$. Jika nilai indeks kesamaan jenis makin dekat pada nilai
$100 \%$, berarti dua kawasan yang dibandingkan tersebut memiliki komposisi jenis (jumlah jenis dan jumlah individu seluruh jenis) relatif sama. Dan apabila makin dekat dengan nilai $0 \%$, maka menunjukkan komposisi jenis makin berbeda. Suatu komunitas yang dibandingkan dapat dikatakan relatif sama jika IS $>50 \%$ (Soerianegara dan Indrawan, 2008).

\section{Indeks Kepadatan Jenis}

Kepadatan burung dihitung berdasarkan jumlah individu setiap jenis burung dibagi jumlah luasan jalur contoh pada masing-masing tipe ekosistem (individu/ha). Dari hasil perhitungan indeks kepadatan jenis burung diurnal pada 
ekosistem hutan rawa sekunder terhitung indeks kepadatan (Di) tertinggi pada jenis Layang Batu (Hirundo tahitica) dengan nilai $\mathrm{Di}=23,21$, pada semak belukar rawa terhitung indeks kepadatan (Di) tertinggi pada jenis Layang Batu (Hirundo tahitica) dengan nilai $\mathrm{Di}=18,45$, dan pada tipe ekosistem pertanian lahan kering terhitung indeks kepadatan (Di) tertinggi pada jenis Burung pipit(Lonchura punctulata) dengan nilai $\mathrm{Di}=28,27$.

Hasil penelitian ini telah memberikan informasi penyebaran dan populasi burung pada setiap tipe ekosistem di Desa Bukit Batu yang digunakan sebagai informasi dalam menyusun kriteria dan indikator dalam penetapan dan pengelolaan konservasi di Desa tersebut.

Berdasarkan hasil dari perhitungan indeks kepadatan jenis burung diurnal dilokasi penelitian diperoleh jumlah jenis dan kepadatan yang berbeda-beda. Menurut Alikodra (1990), kepadatan populasi satwaliar akan bervariasi menurut wilayah dan tipe habitat, termasuk klas burung. Faktor-faktor yang dapat mempengaruhi ukuran dan kepadatan populasi adalah kondisi iklim, kemampuan adaptasi suatu jenis satwaliar, interaksi antara individu maupun antara jenis dan penyakit. Lamber (1992) dalam Partasasmita (2003) menambahkan bahwa perubahan vegetasi dalam suatu ekosistem dapat mempengaruhi burung-burung yang hidup di dalamnya, baik mengenai komposisi komonitas maupun kebiasaan hidupnya.

\section{Kesimpulan}

Keanekaragaman jenis burung tertinggi dilihat dari nilai keanekaragaman jenis berdasarkan indeks Shannon Weinner (H) adalah tipe ekosistem semak belukar rawa yaitu 2,32. Berdasarkan nilai tersebut, keanekaragaman jenis $(\mathrm{H})$ dikatagorikan sedang. Keanekaragaman jenis ini berkaitan dengan struktur dan komposisi vegetasi disetiap lokasi pengamatan.

Berdasarkan status perlindungannya terdapat 3 jenis burung yang dilindungi dalam status perlindungan Republik Indonesia yaitu Tiong mas (Gracula regiliosa), Kipas belang (Rhipidura javanica), dan Burung madu bakau (Leptoma sperata), 26 jenis burung dengan status Least concern, Near Threatened termasuk kedalam IUCN (International Union for Conservation of Nature and Natural Resources) dan 4 jenis burung yang termasuk kedalam status CITES (appendix I dan appendix II), 1 jenis burung migran dan tidak ada jenis burung yang termasuk endemik pulau kalimantan.

\section{Saran}

Penelitian jenis burung diurnal di Desa Bukit Batu ini perlu dilakukan secara berkala pada setiap musim atau tahun, sehingga data dan informasi keberadaan jenis burung dapat diperbaharui dan dapat diketahui jumlah jenis burung yang terdapat di desa tersebut.

\section{DAFTAR PUSTAKA}

Alikodra, H. S. 1990. Penggelolaan Satwa Liar. Jilid I. Departemen Pendidikan dan Kebudayaan Direktorat Jendral Pendidikan Tinggi. Pusat Antar Universitas Ilmu Hayati. IPB. Bogor. Hal : 253 .

Daget. 1976. Kriteria Kemerataan. http;//www.elib.pdii.lipi.go.id/ katalog/index.php/searchkatalog/..82 
12/8212.p. diakses tanggal 25 Desember 2017.

Ferianita FM 2008. Metode Sampling Bioekologi. PT Bumi Aksara. Yogyakarta

Hernowo J. B. 1989. Suatu Tinjauan Terhadap keanekaragaman Jenis Burung dan Peranannya di Hutan Lindung Bukit Soeharto, Kalimantan Timur. Media Konservasi Vol.II,1932.

Kreb CJ. 1978. Ecology: The experimental Analysis of Distribution and Abundance. Second Edition. Institute of Animal Resource Ecology. The Univercity of Britrish Columbia.

MacKinnon J, Phillips K, 1990.Burungburung di Jawa dan Bali. Gajah Mada University Press.Yogyakarta

MacKinnon J, Phillipps K, vanBalen B. 2010. Burung-burung di Sumatera, Jawa, Bali dan Kalimantan. Burung Indonesia. Bogor.

Odum EP. 1993. Dasar-dasar Ekologi. Edisi Ketiga. Universitas Gajah Mada.

Partasasmita, R. 2003. Ekologi Burung Pemakan Buah dan Peranannya Sebagai Penyebar Biji. Makalah
Falsafah Sains Program Pasca Sarjana Institut Pertanian Bogor. Bogor..

Reynold, T.T., J.M. Scott, R.A Nussbanum. 1980. A Variable Circular-plot Method for Estimating Bird Number. The Cooper Ornithologicl Society Condor 82:309 - 313 .

Status Perlindungan Republik Indonesia (A.UU No. 5 tahun 1990; B. PP No. 7 tahun 1999)

Susanti T. 2014 indonesia memiliki 1666 jenis burung dan terkaya jenis endemis [internet]. [diunduh 2017 september 16]. Bogor (ID). Tersedia pada

http://www.burung.org/index.php?o ption $=$ com content $\&$ view $=$ article $\&$ i $\underline{\mathrm{d}=902 \& \text { catid=28\&intemid }=75}$.

Soerinegara dan Indrawan. 2008. Ekologi Hutan Indonesia. Bogor. Laboratorium Ekologi Hutan. Fakultas Kehutanan. Institut Pertanian Bogor.

Utumo A. B. 2010. Indonesia Over Eksploitasi Burung. [Online] Diakses dari: http://palembang.tribunnews.com/0 2/11/2010/indonesia-overeksploitasi-burung. 